\title{
Görsel Sanatlara İlişkin Kişisel İlgi ve Deneyimlerin Temel Tasarım Eğitimine Yansıması
}

\author{
Doç. Dr. Ayşe Tekel \\ Doç. Dr. Nilgün Görer Tamer \\ Arş. Gör. Nihan Oya Memlük \\ Öğr. Gör. Dr. Nilüfer Gürer \\ Arş. Gör. Dr. Aybike Ceylan Kızıltaş \\ Öz
}

Makale Geliş Tarihi: 23.03.2016

Yayına Kabul Tarihi: 21.06.2016

Bu çalışmada, temel tasarım eğitiminde, öğrencilerin görsel algı becerileri ve gelişim düzeyi ile görsel sanatlara ilişkin ilgi ve geçmiş deneyimleri arasındaki ilişkinin sorgulanması amaçlanmaktadır. Gazi Üniversitesi Şehir ve Bölge Planlama Bölümünde temel tasarım dersini ilk kez alan 33 öğrenci üzerinde uygulanan görsel sanatlara ilişkin ilgi ve deneyimleri ölçen anket ve görsel algı düzeylerini belirleyen test çalışması araştırmanın temel veri kaynaklarını oluşturmaktadır. Nitel araştırma yöntemi kullanılarak yapılan çalışmada, anket ve test sonuçları ile öğrencilerin görsel algılarındaki gelişimi izlemek üzere iki boyutlu temel tasarım çalışmalarında sergiledikleri başarı düzeyleri arasındaki ilişki karşılaştırmalı olarak incelenmektedir. Çalışmanın sonuçları, temel tasarım eğitimi öncesinde görsel sanatlara ilgi ve deneyimi olan öğrencilerin olmayanlara oranla görsel algı ve ifade gelişim süreçlerinin daha olumlu olduğunu ve temel tasarım eğitimi ile görsel algının geliştirilebileceğini göstermektedir.

Anahtar Kelimeler: Görsel Algı, Temel Tasarım Eğitimi, Görsel Sanatlar

\section{REFLECTION OF PERSONAL INTEREST AND EXPERIENCE IN VISUAL ARTS TO BASIC DESIGN EDUCATION}

\begin{abstract}
The main aim of this study is to investigate the relationship between student's visual perception skills and level of success through basic design education; and their personal interest and past experiences in visual arts. Questionnaire for determining the level of interest and past experience in visual arts; and test measuring the visual perception skills applied on the 33 students who are taking the basic design course for the first time at Gazi University, City and Regional Planning Department form the main data sources of the research. In this study quantitative research is conducted; in this regard, questionnaire and test results of students are comparatively analyzed with respect to their success levels in two-dimensional basic design works in order to monitor the development in their visual perception skills. The results of the study reveal that, students who have interest and past experience in visual arts tend to express better results in the development of visual perception and communication skills with respect to others, and visual perception skills can be improved with basic design education.
\end{abstract}

Keywords: Visual Perception, Basic Design Education, Visual Arts

Doç. Dr. Ayşe Tekel, Gazi Üniversitesi, Mimarlık Fakültesi, Şehir ve Bölge Planlama Bölümü, Ankara. E-posta: tekelaye@gmail.com

Doç. Dr. Nilgün Görer Tamer, Gazi Üniversitesi, Mimarlık Fakültesi, Şehir ve Bölge Planlama Bölümü, Ankara.E-posta: gorer@gazi.edu.tr

Arş. Gör. Nihan Oya Memlük, Gazi Üniversitesi, Mimarlık Fakültesi, Şehir ve Bölge Planlama Bölümü,

Ankara.E-posta: oyamemluk@gmail.com

Öğr. Gör. Dr. Nilüfer Gürer, Gazi Üniversitesi, Mimarlık Fakültesi, Şehir ve Bölge Planlama Bölümü, Ankara. E-posta: nilufergurer@gmail.com

Arş. Gör. Dr. Aybike Ceylan Kızıltaş, Gazi Üniversitesi, Mimarlık Fakültesi, Şehir ve Bölge Planlama Bölümü, Ankara. E-posta: aybike.ceylan@gmail.com 


\section{Giriş}

Sanat ve tasarım eğitiminin temelini görsel algı oluşturmaktadır. Görsel algı zihinsel süreçlere ve deneyimlere dayanmaktadır (Güngör, 1972: 3; Denel, 1981: 28; Bayraktar vd., 2012: 13). Algı kuramcılarından Gibson (1954) görsel algı gelişiminde deneyimin gerekliliğine; Arnheim (1974) bireyin bilme yetisinin en etkin aracının görme duyusu olduğuna dikkat çekmektedir. Görsel algıya dayalı kuramların odak noktasını ise zihin ve göz arasındaki bağlantılar oluşturmaktadır. Bu kuramların uygulayıcıları, görsel algının başlı başına bir öğrenme biçimi olduğunu savunmaktadırlar (Hortin, 1994: 18). Bu bağlamda, temel tasarım eğitimi görsel algının gelişimine önemli katkı sağlamaktadır. Temel tasarım eğitimi ile özellikle tasarım alanında eğitim gören öğrencilerin kısa sürede bilinçli bir süreç izleyerek tasarım ilkelerini kolaylıkla doğru kodlayıp algılamasına zemin hazırlanmakta; tasarım ilkeleri üzerinden kolay ve anlaşılabilir görsel ortak bir dilin kurgulanması ile ortaya konan ürün için yanılsamalar azaltılmakta; böylelikle görsel algının gelişmesi öğrencilerin tasarım becerilerinin gelişmesine de yardımcı olmaktadır (Güngör, 1972: 24). Bugüne kadar yapılan pek çok araştırmada da temel tasarım eğitiminin öğrencilerin gözlem yapma, algılama, yorum getirebilme, görsel ifade gücünü artırabilme ve bir problem karşısında çözüm geliştirebilme yeteneklerini kazandırdığı belirtilmektedir (Miller ve Prentice, 1996: 812). Benzer şekilde görsel sanatlara ilişkin ilgi ve deneyimde bireyin çevreyi yaratıcı şekilde algılama yetisini arttırmakta; görsel ifade gücünün gelişmesine katkı sağlamaktadır (Usta vd., 2000: 44). Araştırmalar göstermektedir ki, görsel algılama becerisi eğitimle önemli ölçüde değişmekte ve gelişmektedir.

Tasarım öğrencisinin görsel eğitim sürecine oryantasyonunda temel tasarım eğitimi önemli bir rol oynamaktadır. Bu bağlamda Denel (1970) temel tasarım eğitiminin önemini vurgulamakta, temel tasarım eğitimini öğrencinin çevresini algılaması ve tasarlamasında sezgiden öte bir metot sağlayacak bir araç olarak görmektedir. Bu da ancak uygun bir teorik temelle mümkün olmaktadır. Gestalt algı kuramı, tasarım eğitimine nesnelliği sağlayacak teorik temeli oluşturmaktadır. Böylece sadece kabiliyetli ve sezgi sahibi öğrenci değil, bütün öğrenciler 'kişisel bir tasarım felsefesi' geliştirebilmektedir (Denel, 1970: 28-29). Benzer şekilde Günay (2007) da Gestalt teorisini temel alan bir tasarım eğitiminin öğrencilerin görsel algı becerilerinin geliştirilmesindeki önemini vurgulamaktadır.

Gestalt kuramı görsel düzenin oluşturulması ve algılanması için gerekli kavramsal temelleri ortaya koymaktadır. Bu kuram çerçevesinde, 'bütünün parçaların toplamından farklı' olduğu vurgulanmaktadır. Algılama 
eyleminin, bütünün parçalarıile kurulmuşyapısalözellikleriiçerdiğivarsayımı kuramın temelini oluşturmaktadır. Gestalt kuramcılarından Wertheimer (1923/1938) görsel organizasyonun ilkelerinin sezgisel olarak her insanın içinde var olduğunu savunmaktadır. Wertheimer'e göre görsel dünya o kadar karmaşıktır ki insan aklı bu karmaşıklığın üstesinden gelmek için çevresini en basit biçimiyle algılamaya çalışmaktadır. Algı sürecinde birey nesnelerin oluşturduğu bileşimi (kompozisyonu) algılamaktadır (Günay, 2007:110). Gestalt kuramında, parçaların ne tür ilkeler çerçevesinde bütün olarak algılandıkları irdelenmektedir. Bu ilkelerin temelini 'pragnanz' kuralı oluşturmaktadır. Bukurala göre görsel birkompozisyonunalgısı egemen olan koşullar elverdiği ölçüde 'iyi' olarak tanımlanmaktadır. Kompozisyondaki 'iyi' kavramı ile simetri, bütünlük, uyum, düzen ve maksimum basitlik ifade edilmektedir. Maksimum basitlik koşulu her parçanın kompozisyon içindeki 'gereklilik' derecesini ifade etmektedir (Arnheim,2007: 48). Algılama sürecinde 'gruplama' eğilimi ise bireyin başvurduğu önemli araçlardan birisini oluşturmaktadır. Bütünü inşa eden gruplama eğiliminde, yakınlık, benzerlik, kapalılık, iyi devamlılık olarak sıralanan görsel organizasyon ilkeleri her bireyde sezgisel olarak bulunmakta ve bunlar sayesinde karmaşık dünya en basit haliyle algılanabilmektedir. ${ }^{1}$

Öğrencilerin görsel algı ve ifade yetilerinin geliştirilmesini amaçlayan temel tasarım eğitim sürecinde, Gestalt kuramından hareketle bütünü (kompozisyonu) oluşturan parçaların ne tür ilkeler çerçevesinde bir araya gelerek 'iyi' sonuçlanacağı iki ve üç boyutlu çalışmalar ile uygulamalı olarak aktarılmaya çalışılmaktadır. Bu çalışmada öğrencinin görsel algı düzeyinin gelişiminde, temel tasar eğitimi kadar eğitim süreci öncesinde görsel sanatlara olan ilgi düzeyi ve deneyimin de rolü olduğu, iki boyutlu çalışmalardaki başarı durumu ile sorgulanmaktadır.

\section{Yöntem}

Çalışmanın amacı, temel tasarım eğitiminde öğrencilerin görsel algı becerilerinin gelişim düzeyi ile görsel sanatlara ilişkin ilgi ve geçmiş deneyimleri arasında ilişki olup olmadığının sorgulanmasıdır. Çalışmanın temel varsayımı öğrencilerin, görsel sanatlara olan ilgisinin ve deneyiminin, temel tasarım eğitimi öncesi ve sonrasında görsel algı becerilerinin gelişimine katkı sağladığı ve eğitim ile öğrencilerin görsel algı becerilerinin geliştirilebileceği yönündedir.

\footnotetext{
'Benzerlik, yakınlık ve süreklilik gestalt kuramcılarının belirlediği ilk kurallardır. Bunlara daha sonra kapalılık, simetri, aynı doğrultuda olma, okunurluk, ortak yazgı gibi nitelikler eklenmiştir. Gestalt kuralları kimi ilişkileri ve düzenleri tanımlayabilmekte, her zaman açıklayıcı olamamaktadır. Bu durumu gözleyen kuramcılar deneyim olgusunu da gestalt kuralları arasına sokmuşlardır (Günay, 2007: 98).
} 
Nitel araştırma yöntemi kullanılarak gerçekleştirilen araştırmanın çalışma grubunu Gazi Üniversitesi Şehir ve Bölge Planlama Bölümünde 2014-2015 döneminde temel tasarım eğitimini ilk kez alan 33 öğrenci oluşturmaktadır. Çalışma üç aşamadan oluşmaktadır. Çalışmanın ilk aşamasında bu öğrencilerin temel tasarım dersi öncesindeki görsel sanatlara ilişkin ilgi ve deneyimleri tespit edilmekte, görsel algı düzeyleri sorgulanmaktadır.

Temel tasarım dersi öncesinde öğrencilerin görsel sanatlara ilişkin ilgi ve deneyimleri, temel tasarım dersini veren, konusunda uzman öğretim üyeleri tarafından hazırlanan anket aracılığı ile tespit edilmektedir. ${ }^{2}$ Ankette öğrencilerin görsel sanatlara ilişkin uygulamalı deneyimleri; resim, fotoğraf vb. kurslara katılım; görsel sanatlara ilişkin ilgi düzeyleri ise sinema, tiyatro, opera-bale-dans, sergi, festival/bienal gibi etkinliklere gitmek başlıkları altında sınanmaktadır.

Bu öğrencilerin görsel algılama düzeyleri ise görsel algı testi aracılığıyla tespit edilmektedir. ${ }^{3}$ Test, temel tasarım eğitimi öncesinde öğrencilerin görsel algı düzeylerini anlamaya yardımcı olmak üzere dersin öğretim üyeleri tarafından, farklı kaynaklardan taranarak elde edilen görsellerden oluşmaktadır. Bu test de öğrencilerin parça-bütün, şekil-zemin ilişkisini kavrama düzeyleri değerlendirilmektedir. Görsel algı testleri aracılığı ile gözün amaca yönelik görme eylemine odaklanması ve görsel algının yeniden inşasına yardımcı olmak hedeflenmektedir. Bu testte yer alan dört soru (Şekil 1) ve sorulardan beklenilen değerlendirmeler aşağıda kısaca özetlenmektedir.
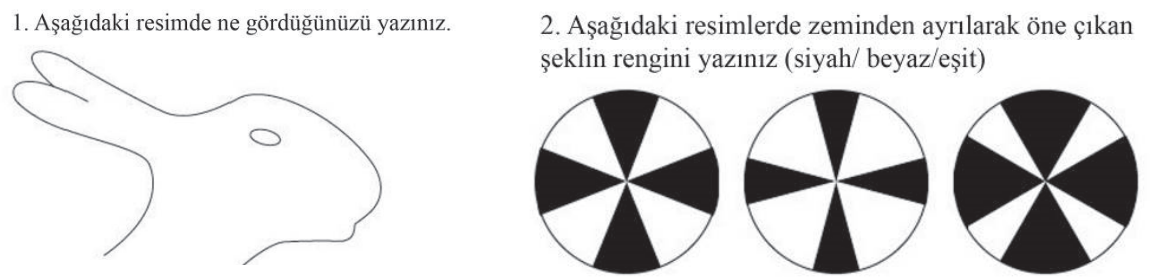

Şekil I: Görsel Algı Testi Soruları

Şekil I.I. Iki bă̆ımsız figür ilişkisi

Şekil I.2. Şekil zemin ilişkisi

\footnotetext{
${ }^{2}$ Anket uygulaması Gazi Üniversitesi Şehir ve Bölge Planlama Bölümüne ortaöğretimden nasıl bir donanım ile öğrencinin geldiğini tespit etmek ve değerlendirmek üzere yapılan derse özgün bir uygulamadır.

${ }^{3}$ Tam anlamıyla bir yetenek ve performans testi olmayan görsel algı testinde öğrencinin görsel bir okuma yaparak test sorularını yanıtlaması beklenmektedir. Görsellerle ilgili sorulan soruların geçerli tek bir yanıtı bulunmaktadır. Öğrencinin sahip olduğu görsel idrak düzeyi vereceği doğru yanıt sayısını belirlemektedir. Bu açıdan test, bilgi düzeyi ölçen standart test grubu içinde değerlendirilebilir. Ancak bu “bilgi” gözün nasıl algıladı̆̆ını anlamaya yöneliktir.
} 


\section{Așağıdaki dikdörtgenler üzerine çizilen şekiller arasında nasıl bir ilişki vardır?}
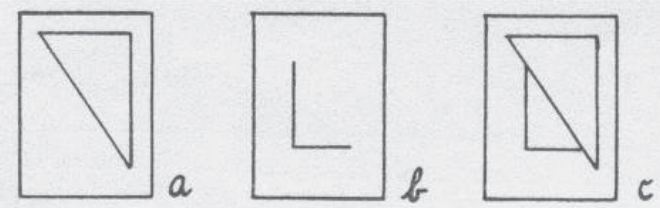

Şekil I.3. Figürler arasındaki ilişki

4. Kareler içinde dairenin en çok dengede olduğu kare dir. en az dengede olduğu kare dir.
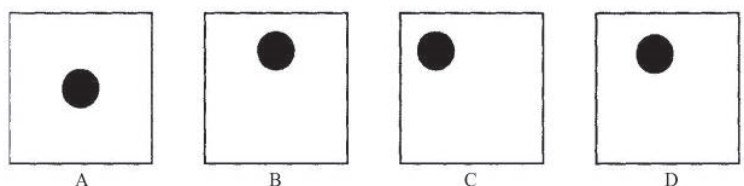

Şekil I.4. Referans çerçevesi içinde siyah nokta için konum denge ilişkisi

Öğrencinin birinci soruda, birbiri içindeki iki bağımsız figürü; ikinci soruda, şekil zemin ilişkisini kavramaya yönelik olarak sınırlandırılmış bir yüzeyde şekli arka plandan farklı olarak algılaması; üçüncü soruda, parçalar arasındaki ilişkiyi yalın bir şekilde ifade etmesi; dördüncü soruda ise sınırları tanımlanan bir yüzey üzerinde siyah noktaların denge durumunu kenarlara referansla görsel olarak, okuması beklenmektedir.

Çalışmanın ikinci aşamasında çalışma grubunda yer alan öğrencilerin temel tasarım dersinde şekil zemin ilişkisi ve ritim temalı iki boyutlu kompozisyonlarda gösterdikleri başarı düzeyleri değerlendirilmektedir. ${ }^{4}$ İlk çalışmada, tasarım alanında "koyduğun koymadığını var eder" ilkesi çerçevesinde şekil zemin ilişkisinin (Şekil 2) içselleştirilmesi beklenmektedir.

${ }^{4} \mathrm{Bu}$ değerlendirme uzman 6 öğretim üyesi tarafinda yapılmıştır. 


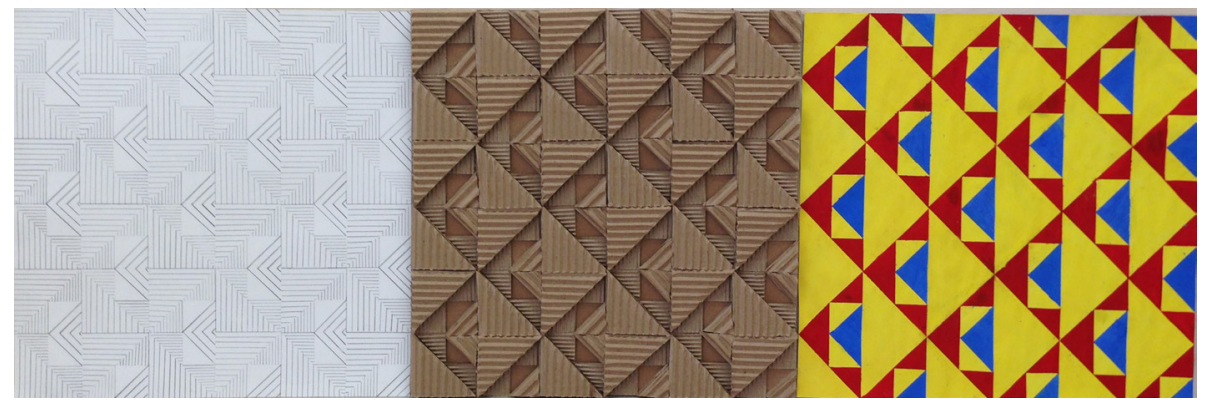

Şekil 3: Ritim Temalı Kompozisyonlar

Şekil 3. I. Çizgi, doku ve renk kullanımı.

Yağmur Polat, Ritim, 2014, çizgi, doku ve renk, 33 ×99cm

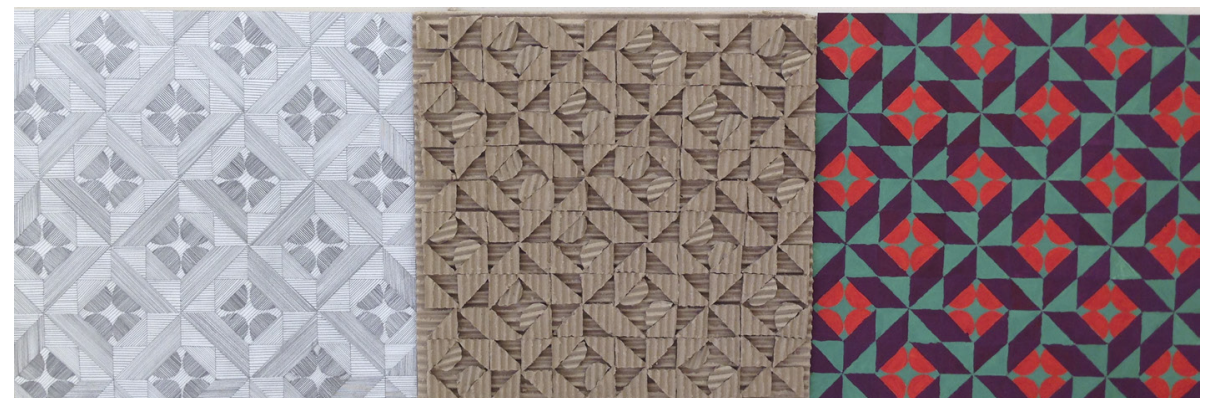

Şekil 3: Ritim Temalı Kompozisyonlar

Şekil 3.2. Çizgi, doku ve renk kullanımı

Şule Algül, Ritim, 2014, Çizgi, Doku ve Renk, 33×99cm

Çalışmanın üçüncü aşamasında öğrencilerin görsel sanatlara ilişkin ilgi ve deneyimleri, görsel algı testindeki başarı düzeyleri ile temel tasarım dersinde şekil-zemin ve ritim çalışmalarındaki başarı durumları arasındaki ilişki karşılaştırmalı olarak sorgulanmaktadır. Karşılaştırmalar iki adımda yapılmaktadır. İlk adımda, öğrenciler sanatın herhangi bir dalını deneyimleyen (resim, heykel, el sanatları, fotoğraf vb. kurslara katılmak / hobi-boş zaman aktivitesi olarak uğraşmak) ve deneyimlemeyen şeklinde iki gruba ayrılmakta; bu grupların iki boyutlu kompozisyon çalışmalarındaki başarı düzeyinde farklıık olup olmadığı karşılaştııılmaktadır. İkinci adımda, öğrenciler görsel sanatlara ilişkin ilgi düzeyleri açısından sosyo-kültürel etkinliklere (sinema, tiyatro, opera-bale-dans, sergi, festival/bienal vb.) gitme/ izleme sıklıklarına göre üç gruba ayrılmakta; bu grupların iki boyutlu kompozisyon çalışmalarındaki başarı düzeyinde farklılık olup olmadığı, başarı düzeyleri ile görsel algı düzeyleri arasında bir ilişki olup olmadığı karşılaştırılmaktadır. 


\section{Bulgular}

Çalışmanın ilk aşamasında 33 öğrenci görsel sanatlara ilişkin kurslara aktif olarak katılıp, katılmama durumlarına göre 2 gruba ayrılmış; bu öğrencilerin şekil-zemin ve ritim temalı çalışmalarının her birinde aldıkları ortalama başarı notu hesaplanarak, genel sınıf ortalaması ve diğer grup eğilimleri ile karşılaştırılmıştır. Sonuçta öğrencilerin görsel sanatlara ilişkin uygulamalı deneyimleri (resim, fotoğraf vb. kurslara katılım) ile çalışmalardaki başarılarının arasında doğru orantılı bir artış olduğu; görsel sanatlara ilişkin uygulamalı deneyimleri olan öğrencilerin başarı ortalamalarının genel sınıf ortalamasının üzerinde olduğu gözlemlenmiştir.Genel ortalamaya bakıldığında ise eğitim sürecinde genel başarı seviyesinin de arttığı ortaya çıkmıştır. Bu sonuç, temel tasarım eğitim sürecinin öğrencinin görsel algı becerilerini geliştirmek yönünde olumlu sonuçlar verdiğini göstermiştir (Grafik 1).

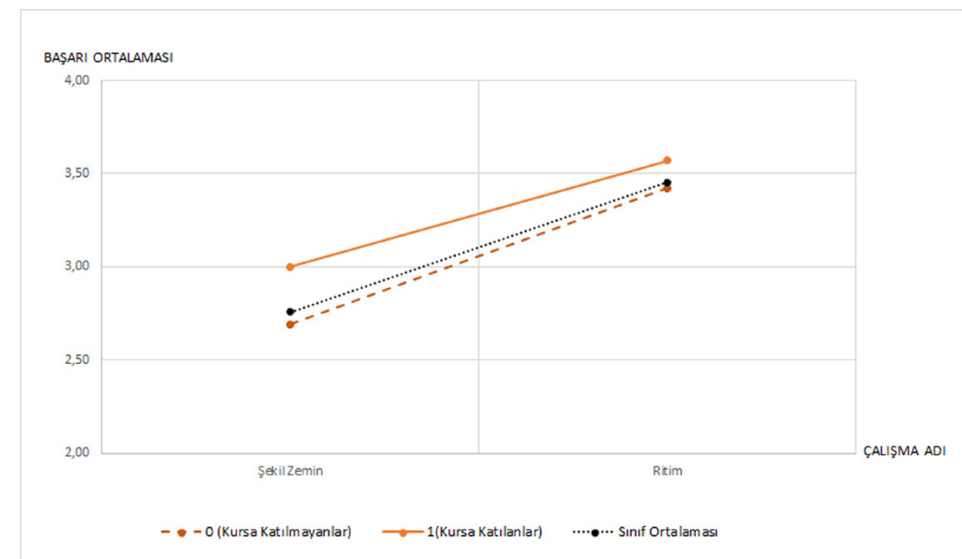

Grafik I. Öğrencilerin Görsel Sanatlara illişkin Uygulamalı Deneyimleri (Görsel Sanat Kurslarına Katılım) ile Şekil-Zemin ve Ritim Çalışmalarındaki Başarılarının Karşılaştırılması

Çalışmanın ikinci aşamasında ise, öğrenciler boş zaman aktivitesi olarak görsel sanatlara ilişkin (resim, heykel, el sanatları, fotoğraf vb.) aktiviteleri tercih etme sıklıklarına dayalı olarak, bir diğer deyişle görsel sanatlara ilgi düzeylerine göre 3 gruba ayrılmıştır (1. Grup: ilgisi düşük seviyede olan öğrenciler, 2. Grup: ortalama ilgiye sahip öğrenciler ve 3. Grup: ilgisi yüksek olan öğrencileri içermektedir). Bu öğrencilerin şekil-zemin ve ritim çalışmalarının her birinde aldıkları ortalama başarı notu hesaplanarak, genel sınıf ortalaması ve diğer grup eğilimleri ile karşılaştııılmıştır. Sonuçta görsel sanatlara ilişkin ilgi düzeyi arttıkça temel tasarım çalışmalarındaki 
başarı oranının da arttığı görülmüştür. Bu durum, görsel sanatlara ilişkin ilginin temel tasarım çalışmalarında başarıyı olumlu etkileyen bir diğer faktör olduğunu ortaya koymuştur (Grafik 2).

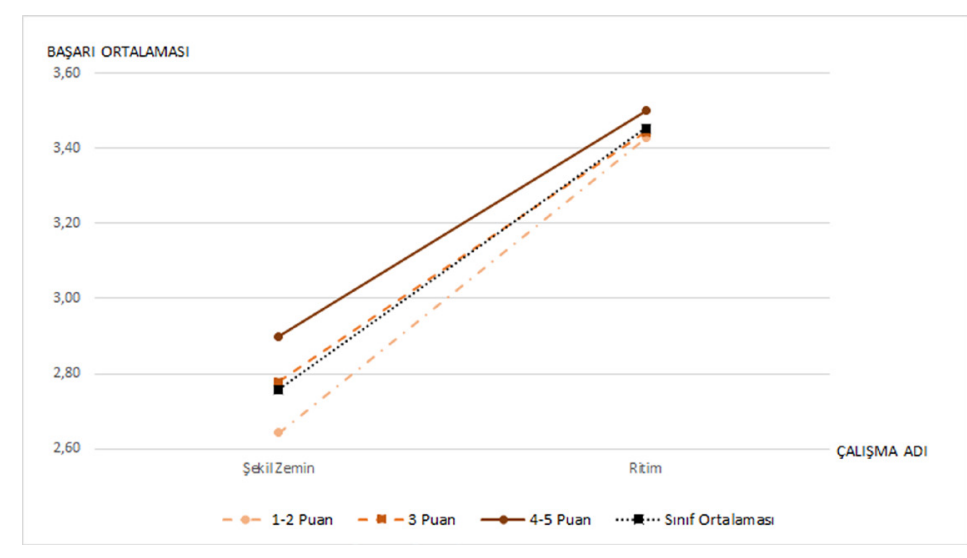

Grafik 2. Öğrencilerin Görsel Sanatlar Ile ilintili Etkinliklere

Ilgi Düzeyi ile Şekil-Zemin ve Ritim Çalışmalarındaki Başarılarııın Karşılaştııılması

$\mathrm{Bu}$ analizlere ek olarak, öğrencilerin görsel sanatlara ilişkin aktivitelere katılıp, katılmama durumları ile görsel algı testindeki başarı düzeyleri arasındaki ilişkide incelenmiştir. Sonuç olarak bu aktivitelere katılma düzeyi yüksek olan öğrencilerin görsel algı testinden de yüksek puanlar aldığı ortaya çıkmıştır. Bu durum, öğrencilerin görsel algı becerileri ile görsel sanatlara ilişkin aktivitelere katılım düzeyleri arasında da bir ilişkili olabileceğini ortaya koymuştur (Grafik 3).

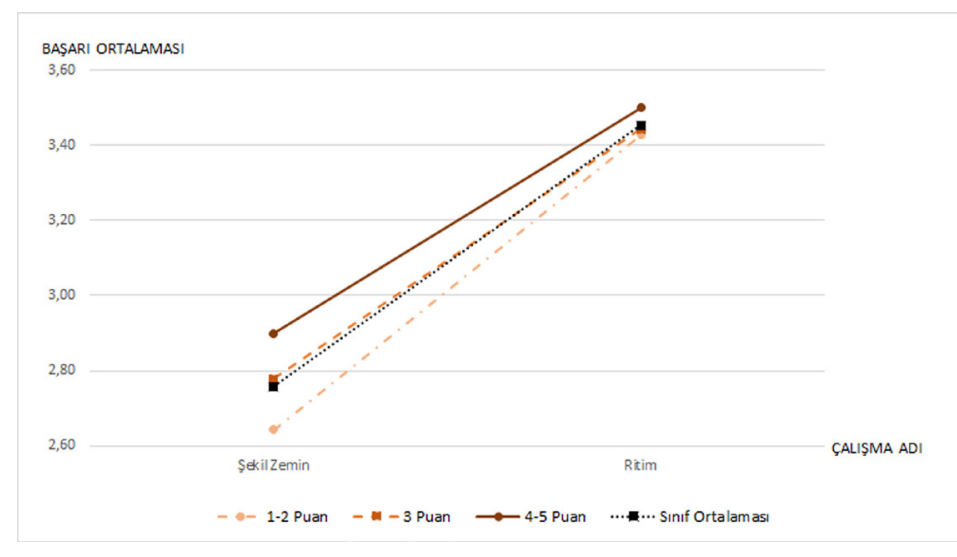

Grafik 3. Öğrencilerin Görsel Sanatlara Ilişkin Etkinliklere Katııım Düzeyi ile Görsel Algı Testi Puanının Karşılaştırıması 
Temel tasarım dersinde verilen eğitimin başlıca hedeflerinden birisi öğrencilerin görsel algılarının geliştirilmesidir. Tasarım bilgisi, gerek zihinsel süreçlere gerekse deneyimlere dayanmaktadır. Duyular, deneyimler ve zihin arasında kurulan bağlantı, olgular ve nesneler arasındaki ilişkilerin doğru tanımlanmasını sağladığından, tasarım sürecinde öğrencinin görsel algı düzeyinin de önemli bir rol oynadığı sonucuna ulaşıımıştır. Ayrıca, yapılan çalışmada öğrencilerin temel tasarım eğitimindeki başarı düzeylerinin görsel algı düzeylerindeki farklılıktan kaynaklandığı ve bu farklılığın doğrudan görsel sanatlara olan ilgileri ile açıklanabileceği sonucuna varılmıştır.

\section{Sonuç}

Çalışmanın sonuçları temel tasarım eğitimi öncesinde görsel sanatlara ilişkin ilgi ve deneyimin, öğrencilerin görsel algılarının gelişmesine katkı koyduğunu, temel tasarım eğitim sürecinde öğrencinin görsel algı becerilerinin de geliştiğini ortaya koymaktadır. Ayrıca, öğrencilerin görsel sanatlar ile ilgili doğrudan deneyimi olmasa da görsel sanat etkinliklerine gitmesinin, izlemesinin görsel algı düzeyini geliştirici etkisinin olduğu görülmektedir. Çalışmanın sonuçları ayrıca her insanda sezgisel olarak var olduğu savunulan görsel algıbecerilerinin tasarımeğitimiile geliştirilebileceği de göstermektedir. Zihinsel süreçlerin, gözün gördüğünü doğru olarak kodlayıp algılamasına zemin hazırlayan görsel algı eğitimi, görsel algının gelişmesi, tasarım becerilerinin ve yaratıc fikirlerinin gelişmesine de fırsat yaratmaktadır.

Günümüzde görsel iletişimin (internet, sosyal medya kullanımı gibi) ağırlık kazanması, doğrudan görsel algı konusundaki temel ilkelerin kullanım alanını da genişletmektedir. Dolayısıyla görsel algının geliştirilmesini sağlayan temel tasar eğitimi de giderek yaşamsal bir önem arz etmektedir. Bu nedenle görsel algının geliştirilmesi, yaratıcılığın desteklenmesi için orta öğretim programlarında, görsel sanatlar eğitimi ile birlikte temel tasarım eğitimine de yer verilmesi önerilmektedir. 


\section{Kaynakça}

Arnheim, R. (2007). Görsel Düşünme, (1. Baskı), Çev: Rahmi Öğdül. İstanbul: Metis Yayınları.

Arnheim, R. (1974). Art and Visual Perception: A Psychology of the Creative Eye, The New Version. Berkeley, California: University of California Press.

Bayraktar, N., Görer Tamer, N., Tekel, A., Gürer, N., Kızıltaş, A., Armatlı Köroğlu, B. (2012). Görsel Eğitimde Yaratıcılık ve Temel Tasarım. Ankara: Nobel Akademik Yayıncılık.

Denel, B. (1970). Tasarım Üzerine Bir Deneme. İstanbul: Yükselen Matbaacilık.

Denel, B. (1981). Temel Tasarım ve Yaratıcılık, ODTÜ Mimarlık Fakültesi Basım İşliği, Ankara.

Gibson, J.J. (1954). 'The Visual Perception of Objective Motion and Subjective Movement', Psychological Review, 6, 304-314.

Günay, B. (2007). 'Gestalt Theory and City Planning Education', Journal of the Faculty of Architecture METU, 24(1), 93-113.

Güngör, i..H. (1972). Temel Tasar. İstanbul: Çeltüt Matbaacılık.

Hortin, J. A. (1994). Theoretical Foundations of Visual Learning, içinde Moore, D. M. ve Dwyer, F. M. (derleyen), Visual Literacy - A Spectrum of Visual Learning: 5-29. New Jersey: Educational Technology Publications.

Miller D.T., Prentice, D.A. (1996). The Construction of Social Norms and Standards. In: Higgins FT, Kruglanski AW (derleyen), Social Psychology: Handbook of Basic Principles. New York: Guilford: 799-829.

Usta G. K., Özdemir I. M., Kuloğlu N., Ustaömeroğlu A. A., Beşgen A., Vural S. (2000). 'Mimarlık Eğitiminde Temel Tasarımın Yeri'. Mimarlık. 293, 41-44.

Wertheimer, M. (1923/1938). Untersuchungenzurlehrevon der Gestalt II. Psychologische Forschung. (Excerpts translated into English as 'Laws of organization in perceptual forms' in Ellis, W. D. (derleyen), (1938). A sourcebook of Gestalt psychology. London: Kegan Paul, Trench, Trubner\&Company. 


\section{Görsel Kaynaklar}

Şekil 1.1: Shah,P., Miyake, A.(2005). Visuospatial Thinking and Cognition. Cambridge: University Press. içinde (Theduck/rabbit figüre used by Chambers and Reisberg.

Şekil 1.2: Anonim

Şekil 1.3: Arnheim, R. (1974). Art and Visual Perception: A Psychology of the Creative Eye, The New Version. Berkeley, California: University of California Press.

Şekil 1.4: Lehar, S. (2003). The World in Your Head, A Gestalt View of the Mechanism of Conscious Experience. London: Lawrence Erlbaum Associates Publishers.

Şekil 2.1, 2.2, 3.1, 3.2: Gazi Üniversitesi Mimarlık Fakültesi Şehir ve Bölge Planlama Bölümü Şehircilik Projesine Giriş (ŞBP 163) Atölyesi Öğrenci Çalışmaları, 2014/15 Dönemi Arşivi.

Grafik 1, 2, 3: Bu çalışmanın yazarları tarafından hazırlanan bu makalenin araştırma sonuçlarının görsel ifadesi. 